\title{
Riscos Ergonômicos dos Profissionais de Enfermagem em Unidade de Terapia Intensiva Adulta: Uma Revisão de Literatura
}

\section{Ergonomic Risks of Nursing Professionals in the Adult Intensive Care Unit: A Literature Review}

\author{
${ }^{1}$ Gracielli Maria da Silva Batista, ${ }^{2}$ Dra Joceli Fernandes Alencastro Bettini de Albuquerque Lins, \\ ${ }^{3}$ Ms Jocilene de Carvalho Miraveti, ${ }^{4}$ Dra Marília Duarte Valim
}

\begin{abstract}
${ }^{1}$ Discente do curso de pós-graduação em Engenharia e Segurança do Trabalho, da Universidade Federal de Mato Grosso - UFMT. (graciellibatista@gmail.com)

${ }^{23}$ Docentes do curso de pós-graduação em Engenharia e Segurança do Trabalho, da Universidade Federal de Mato Grosso - UFMT.

${ }^{234}$ Docente da Faculdade de Enfermagem - UFMT.
\end{abstract}

\begin{abstract}
Enviado em: abril de 2016. Aceito em maio de 2016. Publicado em: novembro de 2016
RESUMO:A ergonomia é o estudo científico que busca proporcionar a interação do homem com o seu ambiente de trabalho, adaptando-o como forma de promover conforto e segurança. Desta forma, oobjetivo deste trabalho consistiu em realizar uma revisão bibliográfica sobre os riscos ergonômicos aos quais os profissionais de enfermagem estão expostos com maior frequência em unidade de terapia intensiva adulto. A revisão de literatura feita juntamente com o levantamento de dados, realizado no mês de fevereiro de 2016, nas bases de dados da Literatura Latino-Americana, do Caribe em Ciências da Saúde (Lilacs), Scientific Electronic Library Online (Scielo) e Google Acadêmico, onde foi selecionado para análise publicações do período de 2010 a 2015 . Os profissionais de enfermagem em unidade de terapia intensiva estão expostos a vários tipos de riscos: físico, químico, biológico, acidente, psicossociais e ergonômico. Sobre os riscos ergonômicos, objeto de estudo, se deve ao fato que atividade laboral depende de grande esforço do profissional e devido ao paciente estar em estado grave e acamado, necessitar de auxílio para movimentar-se,acarretando no desgaste físico do profissional e forçando membros superiores, inferiores e a coluna. Assim observou-se que os riscos ergonômicos nas UTIs são provenientes da movimentação de pacientes em estado delicado de saúde e pela falta de materiais e equipamentos adequados.
\end{abstract}

Palavras-chaves:Ergonomia; UTI Adulto; Riscos Ergonômicos.

ABSTRACT: Ergonomics is the scientific study that seeks to provide the interaction of man with his working environment, adapting it as a way to promote comfort and safety. Thus, the objective of this study was to conduct a literature review on the ergonomic risks to which nursing professionals are exposed more frequently in adult intensive care unit. The literature review made with data collection, held in February 2016, in the Latin American databases, the Caribbean Health Sciences (Lilacs), Scientific Electronic Library Online (Scielo) and Google Scholar where he was selected for analysis of publications from 2010 to 2015. the nurses in the intensive care unit are exposed to various types of risks: physical, chemical, biological, accident, psychosocial and ergonomic. On the ergonomic risks, object of study, is due to the fact that labor activity depends on great effort of professional and due to the patient being in serious and bedridden state, needs assistance to move, resulting in physical professional wear and forcing members top, bottom and the column. Thus it was noted that the ergonomic risks in ICUs are from moving patients in poor health and lack of materials and devices.

Keywords: Ergonomics; Adult ICU; Ergonomic risks.

\section{INTRODUÇÃO}

Hospitais são ambientes nos quais os profissionais de enfermagem estão expostos a todos os tipos de riscos, inerentes ao tipo de atividade laboral que exercem, uma vez que tem contato com pacientes que sofrem de várias enfermidades em especial as Unidades de Terapia Intensiva (UTIs), locais onde pacientes que exigem maiores cuidados, tanto no tratamento quanto em sua movimentação, estão alocados.

A preocupação com a saúde dos trabalhadores de ambientes hospitalares no Brasil, na década de 70, levou pesquisadores da Universidade de São Paulo a iniciarem estudos relacionados com a saúde ocupacional destes 
profissionais (BENATTI; NISHIDE, 2000).

Em UTIs vários fatores afetam a execução dos procedimentos realizados nos pacientes, tais como: movimentação comprometida devido ao pequeno espaço físico, quantidade de profissionais as vezes insuficiente, alguns equipamentos são inadequados (camas sem travas nas rodas, macas e cadeiras de rodas sem manutenção), ocasionando assim lesões dorsais nos enfermeiros entre outras doenças (GALLASH; ALEXANDRE, 2003).

O estudo da ergonomia pode ser utilizado como forma de prevenir o desenvolvimento de enfermidades dorsais em profissionais de enfermagem, por meio da realização de treinamentos e da promoção de programas ergonômicos de prevenção de lesões musculoesqueléticas nos trabalhadores (GALLASH; ALEXANDRE, 2003).

A tecnologia proporcionou, com o tempo, melhorias nos ambientes das UTIs $\mathrm{e}$ as normativas garantiram o quantitativo de pessoal. Contudo, a problemática relacionada aos riscos ergonômicos ainda persiste.

Com o intuito de minimizar esses riscos é necessário que se implante medidas de promoção à saúde e segurança não só dos enfermeiros, que é o objeto de estudo deste trabalho, mas de todos os profissionais inseridos em ambientes hospitalares. Com isso em mente o objetivo deste trabalho consiste em realizar uma revisão bibliográfica sobre os riscos ergonômicos aos quais os profissionais de enfermagem estão expostos com maior frequência em unidade de terapia intensiva adulto.

\section{REFERENCIAL TEÓRICO}

De acordo com Martin e Gadbois (2007), alguns pesquisadores e médicos do trabalho iniciaram a abordagem ergonômica das condições de trabalho por meio de estudos realizados em instituições hospitalares nas quais pouco se interessava em dar uma aplicação prática.

Ainda no entender de Martin e Gadbois (2007), a história da ergonomia pode ser explicada de acordo com o breve resumo que segue abaixo:

A fase dos precursores, que se dá antes de 1970, no qual propõe a humanização do hospital com a finalidade de obter melhorias nas condições de vida dos profissionais de enfermagem. Esta época é marcada pelos estudos (com podômetro) sobre a distância que as enfermeiras percorrem (MARTIN; GADBOIS, 2007).

Os verdadeiros começos (1970 1980) que trazem os estudos realizados por médicos ligados à medicina preventiva, considerando principalmente as análises sobre a carga física que é entendida como o problema mais urgente. Os estudos também incluíram temas relacionados a: custo cardíaco, os efeitos do trabalho noturno em equipe fixa e as medições da força empregada para empurrar carrinhos. Gradativamente o interesse se estende também para a atividade mental e o custo psíquico do trabalho (MARTIN; GADBOIS, 2007).

A terceira fase é apontada pelo crescimento de pesquisas específicas envolvendo: a prevenção de lombalgias, o posto de maqueiro, os suportes de informação nas unidades de tratamento, etc. Nesta fase, diferentes estudos resultaram a partir da proposta de quatro eixos: melhorar o conhecimento hospitalar, aumentar a capacidade de análise dos atores por meio da formação, promover a reflexão sobre a relação entre serviços e levar em consideração as condições de trabalho (MARTIN; GADBOIS, 2007).

$O$ colóquio internacional de ergonomia hospitalar que aconteceu em Paris no ano de 1991 marcou o início de uma nova fase de análise, onde a abordagem em relação às condições ergonômicas de trabalho em hospitais encontrou pessoas interessadas junto aos sindicatos, o que resultou em ações para a 
formação para os delegados sindicais das Comissões de higiene-segurança e condições de trabalho (CHSCT). Esta ação ocorreu em âmbito nacional em centenas de hospitais. No entanto as contribuições da ergonomia ficaram abaixo do que poderia ter sido, mas as perspectivas ergonômicas obtiveram uma ampla abertura no meio hospitalar (MARTIN; GADBOIS, 2007).

Para se obter a saúde e segurança para os trabalhadores do setor hospitalar quanto de setores distintos, se faz necessário que o ambiente de trabalho seja saudável e livre de riscos que comprometam o bem-estar dos profissionais inseridos neste ambiente.

Conforme a Norma Regulamentadora (NR) 10 , risco é a "capacidade de uma grandeza com potencial para causar lesões ou danos à saúde das pessoas". Subentende-se então que risco é a probabilidade de causar dano ao trabalhador devido a exposição em uma determinada situação (SEGURANÇA E MEDICINA DO TRABALHO, 2014).

Ao longo dos anos a ergonomia obteve várias definições .A Société d'ergonomie de langue française (SELF) definiu ergonomia na década de 70 como: a adaptação do trabalho ao homem por meio da aplicação de conhecimentos científicos relacionados ao homem e necessários para considerar as ferramentas, máquinas e dispositivos que possam ser utilizados com o máximo de conforto, segurança e eficácia (FALZON, 2007).

A primeira definição de ergonomia foi proposta pela Associação Internacional de Ergonomia (IEA) a qual refere-se que ergonomia é o estudo científico da relação entre o homem e seu ambiente de trabalho, métodos e meios. Tem o objetivo de elaborar, juntamente com a colaboração das diversas disciplinas científicas que a integram, um conjunto de conhecimentos que, numa expectativa de aplicação, tema finalidade de melhorar a adaptação do homem aos meios tecnológicos de produção e dos ambientes de trabalho e de vida (FALZON, 2007).
Após dois anos de discussão a IEA adotou em 2000 uma nova definição para ergonomia que tornou-se referência internacional, na qual ela é considerada uma disciplina científica que proporciona a interação dos seres humanos com os outros elementos do sistema, e os profissionais que a promovem buscando tornar-se compatível à avaliação das tarefas, meio ambiente e produtos com as necessidades, capacidades e limites das pessoas (FALZON, 2007).

Para Guimarães (2011), a fim de facilitar $\mathrm{o}$ entendimento os fatores humanos devem considerados nos estudos ergonômicos, conforme a Associação Internacional de Ergonomia (IEA) esses fatores são divididos em três domínios:

$\checkmark$ Ergonomia Física que trata das características anatômicas, antropométricas, fisiológicas e biomecânicas do homem em relação à sua atividade física, que incluem tópicos relevantes em relação ao arranjo físico de estações de trabalho, manipulação de matérias, demandas do trabalho e fatores de repetição, vibrações, força e postura;

$\checkmark \quad$ Ergonomia cognitiva que trata dos processos mentais, tais como percepção, atenção, memória, raciocínio e as respostas motoras, considerando a relação da interação das pessoas com os elementos do sistemas e resposta durante sua atuação; e

$\checkmark$ Ergonomia organizacional que trata da otimização dos sistemas sociotécnicos de trabalho participativo e cooperativo, envolvendo a estrutura organizacional, regras e processos, programação de trabalho, trabalho em equipe e satisfação no trabalho.

Avaliando as condições do ambiente a NR 17, (2014) “[...] visa estabelecer parâmetros que permitem a adaptação das condições de trabalho às características psicofísiológicas dos trabalhadores, de modo a proporcionar um máximo de conforto e desempenho eficiente"'(SEGURANÇA E MEDICINA DO TRABALHO, 2014). 
A unidade de terapia intensiva é um dos ambientes mais tensos, agressivos e traumatizantes do hospital, pois se trata de um local que atende pacientes em estado grave de saúde. Essas condições agressivas existentes neste ambiente não impactam apenas nos pacientes, mas em todos os profissionais que ali atuam, em especial os enfermeiros que convivem diariamente com episódios de pacientes graves, pronto atendimento, isolamento e situações de morte (SANTOS et al., 2010).

SANTOS et al. (2010), ainda define a UTI como um ambiente de trabalho que envolve enorme carga emocional, é desgastante e muitas vezes frustrante, ocasionando consequências que comprometem a saúde dos profissionais da saúde.

Tendo em vista este tipo de situação, a função da saúde e segurança do trabalho é promover a preservação da integridade física e mental do trabalhador, no período em que o mesmo exerce suas atividades laborais, através de identificação de fatores que possam interferir em sua saúde (LEITÃO et al., 2008).

Essa identificação se dá por meio de uma abordagem preventiva, rastreamento e diagnóstico precoce de problemas à saúde relacionados ao trabalho, constando casos de doenças profissionais ou danos irreversíveis à saúde do trabalhador. É devido a essas questões que se implementa ações de saúde e segurança do trabalhador, higiene ocupacional e ergonomia (LEITÃO et al., 2008).

\section{MATERIAIS E MÉTODOS}

Trata-se de um estudo do tipo revisão bibliográfica também conhecida como revisão da literatura, parte importante do processo de investigação. Compreende as fases de localizar, analisar, sintetizar e interpretar a investigação prévia realizada em revistas científicas, de temas relacionados com a área de estudo, é uma análise referente aos trabalhos já publicados sobre o assunto objeto de estudo (BENTO, 2012).

O levantamento de dados foi realizado no mês de fevereiro de 2016, sendo utilizadas as seguintes bases de dados: Literatura Latino-Americana e do Caribe em Ciências da Saúde (Lilacs), Scientific Electronic Library Online (Scielo) e Google Acadêmico.

$$
\text { Foram utilizados artigos }
$$

disponíveis no sistema online, publicados em português no período entre 2010 e 2015 que estavam relacionados com o tema do estudo. Utilizou-se também o uso de duas Normas Regulamentadoras, sendo elas NR-10 e NR-17 (SEGURANÇA E MEDICINA DO TRABALHO, 2014).

Realizou-se a busca nas bibliotecas virtuais utilizando os seguintes descritores: Ergonomia, UTI Adulto e Riscos Ergonômicos, sendo que os três descritores foram pesquisados em conjunto.

Os artigos foram escolhidos por meio da leitura dos títulos, selecionando os que tinham relação com o tema do estudo, obtendo um total de 37 artigos. A seguir, realizou-se a análise dos resumos e foram escolhidos apenas os artigos que tinham o mesmo objetivo do estudo, restando apenas 20 artigos. Após a seleção dos artigos realizou-se leitura exaustiva na íntegra separando apenas aqueles que tinham relação com o estudo da pesquisa, restando 14 artigos. E na seleção final realizou-se a classificação dos artigos que compreendiam os anos de 2010 a 2015por se tratar do período de estudo e descartando os que estavam fora deste prazo, permanecendo para análise da pesquisa bibliográfica um total de 7 artigos.

Para facilitar o entendimento realizou-se a análise temática das publicações. Esta análise tem a função de ouvir o autor e aprender sobre ele, sem intervir no conteúdo de sua mensagem, trata-se de fazer uma série de perguntas ao texto como forma de identificar a sua problemática. Captando qual o problema levantado, o autor no decorrer do texto 
responde as questões abordadas, demonstrando assim ao leitor a ideia central do tema ou assunto, possibilitando a compreensão e a formulação do raciocínio lógico sobre a mensagem do autor (SEVERINO, 2000).

Os artigos que foram analisados responderam a seguinte questão: Quais os principais riscos ergonômicos que os profissionais da enfermagem estão expostos na unidade de terapia intensiva adulto?

\section{RESULTADOS E DISCUSSÃO}

Realizada a seleção dos artigos que foram analisados, e que compreende o período de estudo de 2010 a 2015, os artigos foram separados e quantificados de acordo com o exemplificado do gráfico 1 .

Gráfico 1: Artigos publicados no período de 2010 a 2015 no Lilacs, Scielo e Google Acadêmico.

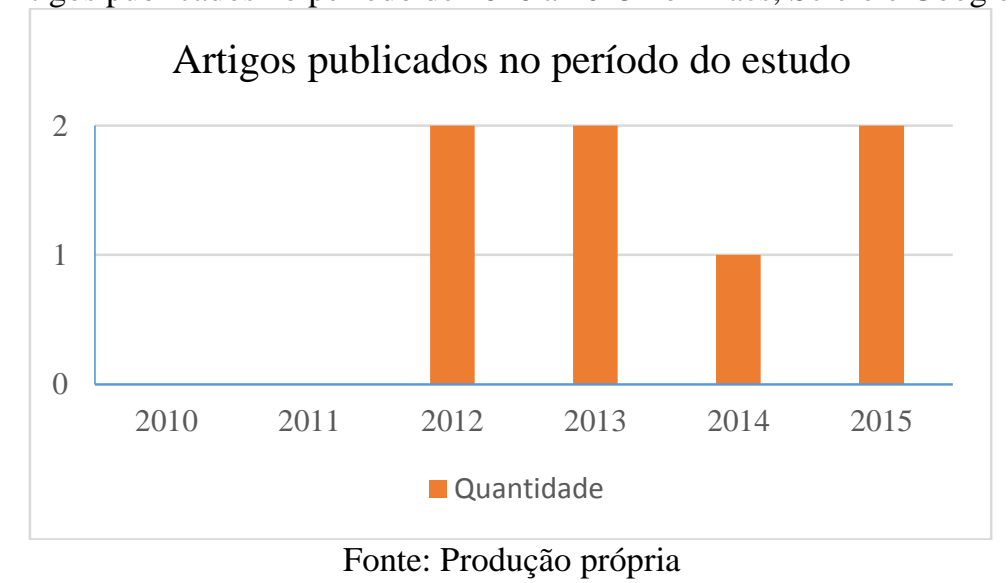

Como pode ser observado no gráfico acima os artigos publicados no período do estudo compreenderam 2 artigos no ano de 2012, 2 em 2013, 1 em 2014 e 2 em 2015 obtendo um total de 7 artigos que foram analisados na produção deste trabalho.
Além da classificação por período, os artigos também foram classificados por tipo de pesquisa no qual se referiram em: revisão bibliográfica, ensaio clínico, revisão integrativa e estudo de caso conforme demonstrado na tabela1. 
Tabela 1: Produções Científicas selecionadas e identificadas relativas aos anos de 2012 a 2015

\begin{tabular}{|c|c|c|c|c|c|}
\hline Ano & Título & Autores & Tipo de Risco & $\begin{array}{l}\text { Tipo de Riscos } \\
\text { Ergonômicos }\end{array}$ & $\begin{array}{l}\text { Método de } \\
\text { Pesquisa }\end{array}$ \\
\hline 2015 & $\begin{array}{l}\text { Riscos } \\
\text { ergonômicos } \\
\text { para } \\
\text { trabalhadores } \\
\text { de enfermagem } \\
\text { ao movimentar } \\
\text { pacientes }\end{array}$ & $\begin{array}{lr}\text { Thiana } & \text { Sebben } \\
\text { Pasa; Tânia Solange } \\
\text { Bosi de } & \text { Souza } \\
\text { Magnago; } & \\
\text { Rosângela } & \text { Marion } \\
\text { da Silva; Anamarta } \\
\text { Sbeghen } & \text { Cervo; } \\
\text { Carmem } & \text { Lúcia } \\
\text { Colomé } & \text { Beck; } \\
\text { Natieli Cavalheiro } & \text { Viero }\end{array}$ & Ergonômico & $\begin{array}{l}\text { - Movimentação e remoção } \\
\text { de pacientes; - Nível de } \\
\text { consciência do paciente; - } \\
\text { Falta de equipamentos e } \\
\text { mobiliários adequados; - } \\
\text { Técnica inadequada }\end{array}$ & $\begin{array}{l}\text { Estudo de } \\
\text { caso }\end{array}$ \\
\hline 2015 & $\begin{array}{l}\text { Risco } \\
\text { ergonômico nas } \\
\text { práticas } \\
\text { equipe } \\
\text { enfermagem } \\
\text { uma UTI }\end{array}$ & $\begin{array}{l}\text { Maykon dos Santos } \\
\text { Marinho; Camila } \\
\text { Tambone } \\
\text { Almeida; Everaldo } \\
\text { Nery de Andrade }\end{array}$ & $\begin{array}{l}\text { Físico, } \\
\text { Acidente, } \\
\text { Biológico e } \\
\text { Ergonômico }\end{array}$ & $\begin{array}{l}\text { - Movimentação de } \\
\text { pacientes; - Pacientes } \\
\text { pesados; - Acelerado ritmo } \\
\text { de trabalho; } \\
\text { Procedimentos repetitivos; } \\
\text { - Falta de materiais e } \\
\text { equipamentos; - Esforço } \\
\text { físico }\end{array}$ & $\begin{array}{l}\text { Estudo } \\
\text { caso }\end{array}$ \\
\hline 2014 & $\begin{array}{l}\text { Lombalgia } \\
\text { ocupacional em } \\
\text { trabalhadores } \\
\text { de enfermagem: } \\
\text { massagem } \\
\text { versus dor }\end{array}$ & $\begin{array}{lr}\text { Talita } & \text { Pavarini } \\
\text { Borges; } & \text { Leonice } \\
\text { Fumiko } & \text { Sato } \\
\text { Kurebayashi; } \quad M^{\mathrm{a}} & \\
\text { Júlia Paes da Silva }\end{array}$ & $\begin{array}{l}\text { Físico, } \\
\text { Químico, } \\
\text { Biológico, } \\
\text { Psicossociais e } \\
\text { Ergonômico }\end{array}$ & $\begin{array}{l}\text { - Manipulação de } \\
\text { pacientes; - Pacientes } \\
\text { inconciente - Organização } \\
\text { do trabalho; - Levantar } \\
\text { peso; Repetitividade de } \\
\text { movimentos; - Duração de } \\
\text { ciclos de trabalho }\end{array}$ & $\begin{array}{l}\text { Ensaio } \\
\text { clínico }\end{array}$ \\
\hline 2013 & $\begin{array}{l}\text { Saúde } \\
\text { ocupacional dos } \\
\text { profissionais de } \\
\text { enfermagem em } \\
\text { unidade de } \\
\text { terapia } \\
\text { intensiva }\end{array}$ & $\begin{array}{lr}\text { Natasha } & \text { Marques } \\
\text { Frota; } & \text { Lívia } \\
\text { Moreira } & \text { Barros; } \\
\text { Luana } & \text { Nunes } \\
\text { Caldini; } & \text { Thiago } \\
\text { Moura de } & \text { Araújo; } \\
\text { Joselany } & \text { Áfio } \\
\text { Caetano } & \end{array}$ & $\begin{array}{l}\text { Acidente, } \\
\text { Biológico, } \\
\text { Químico e } \\
\text { Ergonômico }\end{array}$ & 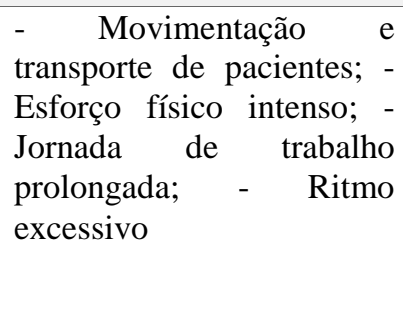 & $\begin{array}{l}\text { Revisão } \\
\text { integrativa }\end{array}$ \\
\hline 2013 & $\begin{array}{l}\text { O cuidador de } \\
\text { enfermagem e o } \\
\text { cuidar em uma } \\
\text { unidade de } \\
\text { terapia } \\
\text { intensiva }\end{array}$ & $\begin{array}{l}\text { Everton Fernandes } \\
\text { Alves }\end{array}$ & $\begin{array}{l}\text { Ergonômico/P } \\
\text { sicológico }\end{array}$ & $\begin{array}{lll}\text { - Movimentação } & \text { de } \\
\text { pacientes; - } & \text { Falta } & \text { de } \\
\text { equipamentos; } & - \text { Falta } & \text { de } \\
\text { recursos humanos } & \end{array}$ & $\begin{array}{l}\text { Estudo de } \\
\text { caso }\end{array}$ \\
\hline 2012 & $\begin{array}{l}\text { Riscos } \\
\text { ocupacionais } \\
\text { relacionados } \\
\text { aos } \\
\text { profissionais de } \\
\text { enfermagem na } \\
\text { UTI: uma } \\
\text { revisão }\end{array}$ & $\begin{array}{l}\text { Géssica dos Santos } \\
\text { Farias; Claudia dos } \\
\text { Santos Oliveira }\end{array}$ & $\begin{array}{l}\text { Físico, } \\
\text { Químico, } \\
\text { Biológico, } \\
\text { Ergonômico e } \\
\text { de Acidente }\end{array}$ & $\begin{array}{l}\text { - Manipulação e transporte } \\
\text { de paciente; - Falta de } \\
\text { equipamentos e mobiliário; } \\
\text { - Organização das tarefas; } \\
\text { - Dimensionamento de } \\
\text { pessoal; - Ritmo de } \\
\text { trabalho acelerado }\end{array}$ & $\begin{array}{l}\text { Revisão } \\
\text { bibliográfica }\end{array}$ \\
\hline 2012 & $\begin{array}{l}\text { Riscos } \\
\text { inerentes ao } \\
\text { trabalho da } \\
\text { equipe } \\
\text { multiprofission } \\
\text { al na unidade } \\
\text { de terapia } \\
\text { intensiva }\end{array}$ & $\begin{array}{l}\text { M }^{\text {a }} \text { Helena de S. P. } \\
\text { Amaral; } \text { M }^{\text {a da }} \\
\text { Penha Pinheiro; } \\
\text { Angela M. La Cava }\end{array}$ & $\begin{array}{l}\text { Físico, } \\
\text { Químico, } \\
\text { Biológico, } \\
\text { Ergonômico/P } \\
\text { sicológico e } \\
\text { Mecânico/Aci } \\
\text { dente }\end{array}$ & $\begin{array}{l}\text { - Exigência de postura } \\
\text { inadequada; - Falta de } \\
\text { adaptação para portadores } \\
\text { de necessidades especiais; } \\
\text { - Mobiliário mal adaptado; } \\
\text { Repetição de tarefas; } \\
\text { Levantamento de peso em } \\
\text { excesso }\end{array}$ & $\begin{array}{l}\text { Estudo } \\
\text { caso }\end{array}$ \\
\hline
\end{tabular}


Como pode ser observado na tabela 1 , todos os artigos estudados apresentam que os profissionais de enfermagem em unidade de terapia intensiva estão expostos aos seguintes tipos de riscos: físico, químico, biológico, acidente, psicossociais e ergonômico, sendo que o risco ergonômico foi o único citado em todas as publicações.

Tal fato deve-se dos profissionais de enfermagem em UTI atendem pacientes que exigem maior conhecimento técnico devido a quantidade de aparelhos que na maioria das vezes devem estar conectados, pelos pacientes necessitarem de banho no leito, alternância de decúbito, por alguns exames serem realizados no leito dependendo do estado de saúde deste paciente. A atividade laboral depende de grande esforço deste profissional e devido ao paciente ser grave e acamado, necessita de auxílio para movimentar-se o que acarretando desgaste físico do profissional, forçando membros superiores, inferiores e a coluna.

Com relação aos fatores de riscos ergonômicos foram organizados nas seguintes categorias: riscos relacionados ao mobiliário e equipamentos, ao trabalhador, à organização do trabalho e devido ao tipo de paciente, conforme o que diz cada autor das publicações estudadas a respeito do assunto:

Fatores de risco ergonômico relacionado ao mobiliário e equipamentos:

Em muitos dos casos os equipamentos utilizados nas UTIs não são adequados, como, por exemplo, as camas sem travas nas rodas e altura ajustável automática, cadeiras de rodas e macas sem manutenção, que podem causar ao trabalhador lesões que o tornem incapacitado para realizar suas atividades.

A respeito dos riscos ergonômicos encontram-se fatos relacionados a levantamento de peso em excesso, mobiliário mal adaptado, repetição de tarefas, falta de adaptação para portadores de necessidades especiais e a exigência de postura inadequada (Amaral et al.,2012).

Durante a remoção e movimentação de pacientes é necessário ter atenção aos fatores de risco que interferem na saúde do trabalhador, como: equipamentos utilizados para essas atividades, posto de trabalho e as condições ergonômicas inadequadas de mobiliários, na maioria das vezes, a movimentação e remoção de pacientes são realizadas com um número inferior de profissionais ao necessário e com equipamentos inadequados, o que aumenta o risco de desenvolver problemas osteomusculares (PASA et al., 2015).

\section{Fatores de risco ergonômico relacionado ao trabalhador:}

Além da carga emocional e estresse que ao qual está exposto, e as das longas jornadas de trabalho, muitos desses profissionais têm dupla jornada de trabalho (dois empregos).

Os profissionais de enfermagem diariamente trabalham em ritmo acelerado, executam atividades que exigem esforço físico, realizam procedimentos que lhes causam cansaço, desânimo, dores no corpo, estresse e essas circunstâncias proporcionam o aparecimento de doenças do trabalho e acidentes (FARIAS; OLIVEIRA, 2012).

Fatores de risco ergonômico relacionado à organização do trabalho:

Os riscos ergonômicos são definidos conforme a Comissão Interna de Prevenção de Acidentes (CIPA) em: exigência de postura inadequada, controle rígido de produtividade, levantamento e transporte manual de peso, imposição de ritmos excessivos, intenso esforço físico, trabalho em turno e noturno, longas jornadas de trabalho, monotonia e repetitividade e outras situações que causam estresse físico e psíquico. Esses fatos ocorrem em UTIs devido a vários casos de pacientes inconscientes, e que dependem totalmente dos cuidados da 
equipe de enfermagem para a realização de todos os procedimentos necessários no tratamento de suas enfermidades (FROTA et al., 2013).

$\mathrm{Na}$ manipulação de pacientes alguns fatores tais como, organização do trabalho, repetitividade de movimentos, levantamento de pesos, empurrar objetos pesados, manter postura que envolve o tronco no movimento de rotação e flexão entre outros são os responsáveis por desencadear a dor na lombar nos profissionais de enfermagem, além da exposição dos riscos físicos, químicos, biológicos, psicossociais e ergonômicos que estes profissionais estão sujeitos em ambiente hospitalar (BORGES et al., 2014).

Fatores de risco ergonômico relacionado ao tipo de paciente:

$\mathrm{O}$ fato de algumas UTIs não possuir equipamentos adequados, materiais $\mathrm{e}$ recursos humanos necessários e suficientes para a realização das atividades laborais, impõem aos profissionais uma sobrecarga de trabalho na movimentação de pacientes pesados em estado crítico de saúde, acarretando aos enfermeiros a incidência de doenças devido a dores em diversas partes do corpo, especialmente na região lombar, ombros, joelhos e região cervical (ALVES, 2013).

Marinho et al. (2015), afirmam que o aparecimento de doenças ocupacionais e acidentes de trabalho são provenientes da movimentação e transporte de pacientes, pois alguns necessitam fazer exames em outras salas, necessitam de banho no leito e mudança de decúbito.

Os riscos ergonômicos podem ser reduzidos dependendo nível de consciência do paciente, pois quanto maior for a dependência do paciente, maior é o esforço físico empregado pelo enfermeiro na atividade de remoção e movimentação, razão pela qual aumentam os riscos de lesões musculoesqueléticas entre os profissionais de enfermagem, associando este fator a falta de materiais adequados para a execução deste procedimento o número insuficiente de funcionários, posturas incorretas e falta de equipamento de elevação do paciente agravando a saúde do profissional (PASA et al., 2015).

Tendo em vista essas situações e a preocupação com o bem estar do profissional e temas relacionados com a saúde do trabalhador surgiram diversas discussões nas últimas décadas, com a intenção de aproximar áreas como a engenharia, psicologia, saúde, entre outras. A contribuição de áreas distintas tem sido importante para a disseminação de assuntos envolvendo questões como riscos ambientais, ergonomia, equipamentos de trabalho, divisão do trabalho e outros, com o intuito de promover um ambiente de trabalho que proteja e previna $o$ trabalhador, proporcionando qualidade de vida (MARINHO et al., 2015).

Os hospitais são os locais de trabalho mais importantes na área da saúde, pois além de nele serem realizadas atividades de assistência médica também são desenvolvidas pesquisas e há a formação de recursos humanos. Concentra os profissionais de saúde que desenvolvem o conhecimento e tecnologia. Devido à grande quantidade de pacientes a rotina hospitalar torna-se uma sucessão de ações e procedimentos com alto grau de risco e responsabilidade sendo mínima a margem de tolerância a erros (AMARAL et al., 2012).

Dentre os profissionais da área da saúde os enfermeiros são os mais afetados por vários riscos ocupacionais, especialmente quando o ambiente de trabalho se trata da Unidade de Terapia Intensiva (UTI). Nesse setor a atividade laboral da equipe de enfermagem é realizada em condições distintas na qual a complexidade e a gravidade dos pacientes estabelecem a necessidade de trabalhar com equipamentos sofisticados, realizar tarefas assistenciais complexas, além do constante ruído dos aparelhos, de o ambiente ser fechado, frio e existir a convivência com vida e morte dos pacientes (FARIAS; OLIVEIRA, 2012). 
Os profissionais de enfermagem merecem atenção no que diz respeito à saúde do trabalhador, pois suas atividades exigem força física durante alguns procedimentos, como por exemplo na movimentação e remoção de pacientes, podendo ocasionar lombalgias a esses trabalhadores, interferindo na eficiência da força e capacidade de trabalho da enfermagem (PASA et al., 2015).

Conforme o relato dos autores das publicações analisadas, o ambiente hospitalar e em especial a unidade de terapia intensiva provoca várias alterações na saúde dos profissionais de enfermagem, tendo em vista que os mesmos estão expostos a vários tipos de riscos, que podem acarretar problemas que os impeçam de realizar suas atividades. Cabe aos gestores, juntamente com os trabalhadores deste ambiente, elaborar e implantar políticas que visem minimizar a exposição dos profissionais a situações que coloquem em risco sua saúde, oferecendo segurança e qualidade de vida para seus funcionários, tornando assim os hospitais em ambientes adequados ao desempenho da profissão de enfermagem.

Com o intuito de minimizar os riscos ergonômicos aos quais os profissionais de enfermagem estão expostos diariamente em UTIs sugere-se que se realize uma análise ergonômica do ambiente, para que se possa ter um maior entendimento dos aspectos que podem ser prejudiciais ao trabalhador, identificando se os riscos estão no mobiliário, equipamentos ou transporte de pacientes, e que medidas podem ser tomadas para evitar que a saúde da equipe de enfermagem seja comprometida.

Algumas modificações tais como treinamento de posicionamento adequado do paciente, maca adequada para transporte e limitar o número de empilhamento de caixas, são atitudes que podem diminuir esse risco (AMARAL et al., 2012).

É fundamental a atenção às situações que envolvam a postura dos profissionais, o mobiliário do setor, o modo como as tarefas são organizadas, a demanda de trabalho, o dimensionamento do pessoal e as características físicas desses profissionais (FARIAS; OLIVEIRA, 2012).

Com relação ao mobiliário e equipamentos: realizar a manutenção adequada dos equipamentos (cadeira de rodas, maca, cama, etc.), aquisição de mobiliário e equipamentos hospitalares considerando fatores ergonômicos, evitar utilizar equipamentos improvisados e capacitar os profissionais no uso de equipamentos modernos (ALEXANDRE, 2001).

Como forma de minimizar os problemas relacionados ao trabalhador que na maioria apresentam problemas decorrentes de movimentos e postura inadequada, implementação de pausas para descanso, treinamento da forma correta de se abaixar e levantar, massagem corporal e a contratação de um fisioterapeuta, para realização de ginástica laboral. E ainda na organização dos postos de trabalho e dimensionamento do pessoal, realizar a distribuição de acordo com a demanda de trabalho e forma física dos profissionais da equipe de enfermagem.

E por último quanto ao tipo de paciente para seu transporte $\mathrm{e}$ movimentação é necessário planejamento, avaliar a capacidade de colaborar em sua movimentação e as suas condições físicas, se está conectado a algum tipo de equipamento (sondas, soros, entre outros), observar o espaço físico e a disposição do mobiliário, abaixar ou elevar a altura da cama para que fique no mesmo nível da maca, travar as rodas da cama, maca e cadeira ou solicitar auxílio adicional e adaptar a altura da cama ao profissional e ao tipo de procedimento que será realizado, o ideal seria a utilização de camas eletrônicas.(ALEXANDRE, 2001). 


\section{CONSIDERAÇÕES FINAIS}

Com este estudo observou-se que a unidade de terapia intensiva é um ambiente que provoca exposição ao risco ergonômico devido ao desgaste físico e mental nos profissionais de enfermagem, além da exposição frequente a riscos de natureza biológica, física, química, psicológica e mecânica que podem comprometer a sua saúde.

Os riscos ergonômicos nas UTIs estão presentes em função dos pacientes que estão com a saúde debilitada e carecem de maiores cuidados em sua movimentação, alternância de decúbito, banho no leito, pois normalmente estão conectados a vários equipamentos, e com isso a equipe de enfermagem precisa empreender muito esforço físico para realizar os cuidados necessários.

Além das atividades rotineiras da equipe de enfermagem no cuidado com os pacientes nas UTIs, estes têm de lidar também com a falta de materiais e equipamentos adequados, o que agrava a saúde laboral do profissional e o desempenho de suas atividades.

É imprescindível que os gestores promovam programas e ações com $\mathrm{O}$ intuito de garantir a saúde e segurança dos profissionais da saúde, seja por meio de treinamentos ou palestras e principalmente envolver os profissionais em projetos que visem a melhoria da qualidade de vida, como por exemplo a busca pela redução das prolongadas jornadas de trabalho, e o investimento em equipamentos e materiais adequados para o desenvolvimento das atividades laborais.

\section{REFERÊNCIAS BIBLIOGRÁFICAS}

ALEXANDRE, Neusa Maria Costa. Recomendações básicas: aspectos ergonômicos e posturais nas atividades dos trabalhadores da área de saúde. In Ferreira et al. Manual sobre ergonomia. Disponível em: <http://www.dgrh.unicamp.br/documentos/ manuais/man_dsso_ergonomia.pdf >. Acesso em: 18 Abr 2016.

ALVES, Everton Fernando. O cuidador de enfermagem e o cuidar em uma unidade de terapia intensiva. UNOPAR Cient Ciênc Biol Saúde 2013; 15(2):11522.

AMARAL, Maria Helena de S. P.; PINHEIRO, Maria da Penha; CAVA, Angela M. La. Riscos inerentes ao trabalho da equipe multiprofissional na Unidade de Terapia Intensiva. Revista Acreditação, v. 1, n. 1, 2011,ISSN: 22375643.

BENATTI, Maria Cecília Cardoso; NISHIDE, Vera Médice. Elaboração e implantação de mapa dos riscos ambientais para prevenção de acidentes em uma unidade de terapia intensiva de um hospital universitário. Rev. LatinoAm. Enfermagem v.8 n.5 Ribeirão Preto out. 2000.

BENTO, Antônio V. Como fazer uma revisão da literatura: considerações teóricas e práticas. Revista JA (Associação Acadêmica da Universidade da Madeira), no 65, ano VII (pp. 42-44). ISSN: 1647-8975, Maio 2012.

BORGES, Talita Pavarini; KUREBAYASHI, Leonice Fumiko Sato; SILVA, Maria Júlia Paes da. Lombalgia ocupacional em trabalhadores de enfermagem: massagem versus dor. Revista da Escola de Enfermagem da USP, v. 48, n. 4, 2014. DOI: 10.1590/S0080623420140000400014 .

FALZON, Pierre. Ergonomia. São Paulo: Editora Edgar Blücher Ltda, 2007.

FARIAS, Géssica dos Santos; OLIVEIRA, Claudia dos Santos. Riscos ocupacionais relacionados aos profissionais de enfermagem na UTI: uma revisão.Brazilian Journal of Health v. 3, n. 1, p. 1 - 12, Jan/Abr 2012. 
FROTA, Natasha Marques; BARROS, Lívia Moreira; CALDINI, Luana Nunes; ARAÚJO, Thiago Moura de; CAETANO, Joselany Áfio. Saúde ocupacional dos profissionais de enfermagem em unidade de terapia intensiva.Revista Oficial do Conselho Federal de Enfermagem, Enfermagem em Foco, eISSN: 2357-707X, i-ISSN: 2177-4285, v. 4, n. 2, 2013.

GALLASH, Cristiane Helena; ALEXANDRE, Neusa Maria Costa. Avaliação dos riscos ergonômicos durante a movimentação e transporte de pacientes em diferentes unidades hospitalares. R. Enferm UERJ 2003, 11:252-60.

GUIMARÃES, Lia Buarque de Macedo. Ergonomia e fatores humanos: bases científicas. In Máculo e Vidal, Ergonomia: trabalho adequado e eficiente. Rio de Janeiro: Elsevier/ABEPRO, 2011.

LEITÃO, Ilse Maria Tigre de Arruda; FERNANDES, Aline Leite; RAMOS, Islane Costa. Saúde ocupacional: analisando os riscos relacionados à equipe de enfermagem numa unidade de terapia intensiva. Cienc Cuid Saude, v. 7, n. 4, out/dez. 2008.

MARINHO, Maykon dos Santos; ALMEIDA, Camila Tambone de; ANDRADE, Everaldo Nery de. Risco ergonômico nas práticas da equipe de enfermagem de uma UTI. C\&D-Revista
Eletrônica da Fainor, Vitória da Conquista, v.8, n.1, p. 192-205, jan/jun. 2015.

MARTIN, Christian; GADBOIS, Charles. A ergonomia no hospital. In Falzon, Ergonomia.São Paulo: Editora Edgar Blücher Ltda, 2007.

PASA, Thiana Sebben; MAGNAGO, Tânia Solange B. de S.; SILVA, Rosângela Marion da; CERVO, Anamarta Sbeghen; BECK, Carmem Lúcia Colomé; VIERO, Natieli Cavalheiro. Riscos ergonômicos para trabalhadores de enfermagem ao movimentar e remover pacientes. Rev. Enferm UFMS 2015, Jan/Mar; 5(1):92-102

SANTOS, Flávia Duarte dos; CUNHA, Mércia Heloísa F.; ROBAZZI, Maria Lúcia do Carmo Cruz; PEDRÃO, Luiz Jorge; SILVA, Luiz Almeida da; TERRA, Fábio de Souza. O estresse do enfermeiro nas unidades de terapia intensiva adulto: uma revisão da literatura. SMAD, Rev. Eletrônica Saúde Mental Álcool e Drogas (Ed port.) ISSN 18066976, v.6 n.1 Ribeirão Preto 2010.

SEGURANÇA E MEDICINA DO TRABALHO. NR-10 Segurança em instalações e serviços em eletricidade. $74^{\mathrm{a}}$ ed. São Paulo: Editora Atlas S.A, 2014.

SEGURANÇA E MEDICINA DO TRABALHO. NR-17 Ergonomia. 74 ${ }^{\mathrm{a}}$ ed. São Paulo: Editora Atlas S.A, 2014.

SEVERINO, Antônio Joaquim. Metodologia do trabalho científico. $21^{\mathrm{a}}$ ed. rev. E ampl. São Paulo: Cortez, 2000. 